\title{
Repeat Previous Treatment
}

National Cancer Institute

\section{Source}

National Cancer Institute. Repeat Previous Treatment. NCI Thesaurus. Code C137867.

Following primary therapy, administration of a second course of therapy. 